See discussions, stats, and author profiles for this publication at: https://www.researchgate.net/publication/325690861

\title{
Comparison and quality testing of polymer non-woven postharvest preservation sheets using $\mathrm{X}$-ray tomography
}

Article in Acta horticulturae · April 2018

DOl: 10.17660/ActaHortic.2018.1201.49

CITATIONS

0

4 authors, including:

Suzane Pols

KU Leuven

1 PUBLICATION O CITATIONS

SEE PROFILE
READS

25

Anton Du Plessis

Stellenbosch University

122 PUBLICATIONS 452 CITATIONS

SEE PROFILE

Some of the authors of this publication are also working on these related projects:

Improving postharvest preservation sheet quality View project

Mechanical Properties of High Performance Concrete with Superabsorbent Polymers (SAP) View project 


\title{
Comparison and quality testing of polymer non-woven postharvest preservation sheets using X-ray tomography
}

\author{
S. Pols ${ }^{1}$, A. du Plessis ${ }^{2,3}$, S.G. le Roux ${ }^{3}$ and F.A. Vries ${ }^{1}$ \\ ${ }^{1}$ Tessara (Pty) Ltd, South Africa; ${ }^{2}$ Physics Department, Stellenbosch University, Stellenbosch, South Africa; ${ }^{3} \mathrm{CT}$ \\ Scanner Facility, Central Analytical Facilities, Stellenbosch University, Stellenbosch, South Africa.
}

\begin{abstract}
Sulphur dioxide $\left(\mathrm{SO}_{2}\right)$ gas is routinely used in the table grape industry as a chemical preservative. A balance between enough gas for decay control and a low enough dose to prevent a phytotoxic effect on the grapes is required. Engineering $\mathrm{SO}_{2}$ generating pads that emit a suitable concentration of gas is therefore of the utmost importance for the table grape industry. The aim of this paper is to demonstrate the development of a novel method through which the quality of $\mathrm{SO}_{2}$ generating pads and the amount of gas it releases can be monitored. The aim of this paper is therefore to demonstrate a high-resolution X-ray tomography methodology designed particularly for the quantitative analysis of polymeric non-woven layered materials used in the production of $\mathrm{SO}_{2}$ generating pads. The quality and structure of the non-woven materials is of interest since it may influence the rate at which the concentration of $\mathrm{SO}_{2}$ is released from the pads. The scanning procedure for this sample type is described in addition to specialized image processing steps, which allow quantitative analysis of various parameters of interest for quality comparison. A quantitative comparison of three commercially available products is included and this demonstrates the potential use of this method in quality control and comparison of different suppliers or competitors. This method could be applied to any low-density fibrous material where fibres have a diameter of more than approximately 6 microns.
\end{abstract}

Keywords: non-woven, non-destructive imaging, X-ray tomography, micro-CT, sulphur dioxide

\section{INTRODUCTION}

For more than half a century sulphur dioxide $\left(\mathrm{SO}_{2}\right)$ has been used as a chemical preservation for the postharvest preservation of table grapes. Currently no other alternative chemical exists with the same level of efficacy against decay development (Gao et al., 2003; Zhang et al., 2003). The $\mathrm{SO}_{2}$ gas can be administered in two different forms, either as a largescale fumigation, or in the form of Sulphur dioxide generating pads $\left(\mathrm{SO}_{2}\right.$ pads $)$.

Container fumigation is conducted at $32^{\circ} \mathrm{F}\left(0^{\circ} \mathrm{C}\right)$ for export markets to preserve fruit and prevent decay development during shipment. Fumigation, however, has various limitations and dangers linked to it. A high concentration of gas is required to reach the surrounding grape atmosphere, but care should be taken that levels do not cause phytotoxicity. Additionally, residue levels need to be kept below $10 \mathrm{ppm}$, as per regulatory requirements (Crisosto et al., 2002; Zoffoli et al., 2008). When fumigation is done, Sulphur powder is burned and subsequently generates $\mathrm{SO}_{2}$. Therefore, finding the perfect level of gas concentration is difficult and in many cases, cannot be controlled as necessary. The fumigation process is also influenced by the type of container, the number and position of fans installed in the container and the air flow channels available in the container. If too much free moisture is present on the grapes and the air flow is not sufficient, the grapes can be damaged. Damages included $\mathrm{SO}_{2}$ burn and micro-cracking of the grape skin (Crisosto et al., 2002).

A suitable alternative to fumigation are the frequently used $\mathrm{SO}_{2}$ pads. They allow for a slow, controlled release of the $\mathrm{SO}_{2}$. It acts as a suitable alternative to fumigation, presenting a 
better controlled balance between the amount of $\mathrm{SO}_{2}$ generated and phytotoxicity. For the $\mathrm{SO}_{2}$ pads, the gas concentration released is heavily dependent on the $\%$ active ingredient included (sodium metabisulphite in this case), temperature, humidity and quality of materials required for production (Crisosto et al., 2002). If the quality is not up to standard, a higher level of $\mathrm{SO}_{2}$ gas will be present which creates a risk of phytotoxicity in the form of burn and hairline cracking, as with fumigation (Zhang et al., 2003). Manufacturing of the $\mathrm{SO}_{2}$ pads requires intensive chemical engineering to prevent these side effects from occurring.

$\mathrm{X}$-ray micro computed tomography (microCT) is an emerging materials analysis tool which is used particularly in cases where non-destructive three-dimensional imaging is advantageous, compared to traditional surface analysis or 2D tools. The method finds application in the visualization of internal details of all kinds of materials without physical sectioning of the sample under investigation. In addition, quantitative analysis is possible in the form of linear or volumetric measurements. The method has recently been reviewed by Maire and Withers (2014) for materials science applications, by Cnudde and Boone (2013) for geoscience applications, and by Schoeman et al. (2016) for food science applications. Non-destructively investigating the internal details of objects finds application in many diverse fields as shown for example in du Plessis et al. (2016a).

One of the major applications of X-ray microCT is the analysis of porosity in 3D, where each pore space is individually measured in terms of volume, surface area and other parameters, for example see the analysis of spherical porosity in concretes in du Plessis et al. (2016b) or small spherical porosity in metal samples in du Plessis and Rossouw (2015). This type of analysis has become routine in the inspection of porous materials, but the analysis becomes a challenge when the total porosity becomes excessively high, leading to pore spaces which are connected with one another in 3D space, as is the case in foam-like materials, meshes or similar low-density materials (with high void:material fractions).

$\mathrm{X}$-ray tomography has been used widely in the characterization and analysis of fibrous materials. For example, Faessel et al. (2005) studied wood fibres in composite wooden materials, using synchrotron X-ray tomography. Krause et al. (2010) studied the fibre orientation in composites and this type of analysis has become routine in the last few years for quality inspection of woven fibre composites. Besides the directionality of the fibres, the porosity of the fibre composites and the porosity within the fibres have been studied widely, see for example a recent study by Madra et al. (2014). Studies have also been conducted on woven fibre composites under load with in-situ X-ray tomography, some recent results are reported in Yu et al. (2016).

Low-density materials similar to polymers such as fuel cells with carbon fibre gas diffusion layers and polymer microporous layers have been analyzed for 3D pore structures and permeability, see for example Ostadi et al. (2010) and Burheim et al. (2015).

X-ray tomography has also been applied to the characterization of non-woven polymer materials in particular, in a study using a combination of X-ray tomography, scanning electron microscopy (SEM) and mercury porosimetry, where the focus was on pore size analysis (Manickam and McCutcheon, 2012). In another study the use of X-ray tomography was demonstrated for characterization of fibre orientation of non-woven polymer fibre fabrics (Soltani et al., 2015).

Here we report on the methodology not particularly for porosity or fibre orientation, which has been the focus of most studies, but more generally for a variety of parameters that can assist in the quality inspection and for comparison of different non-woven materials manufactured in different processes. This demonstrates the wider type of microstructural information that can be gained relatively simply in laboratory X-ray tomography facilities and how this can assist in understanding the material structures of interest. In this paper we focus particularly on non-woven polypropylene materials containing a slow-release preservative used for the post-harvest preservation of various fruits. Different manufacturing methods produce different variations of the non-woven material, which could influence the release rate of the preservative enclosed in the sheet. Besides the release rate, the integrity of the sheet and prevention of possible delamination is essential. The microstructural information gained from microCT could be correlated with the actual 
performance observations of the different non-woven sheets.

\section{MATERIALS AND METHODS}

Samples were supplied in sheets and $2.5 \mathrm{~mm}$ squares were sectioned from each nonwoven sheet for high resolution X-ray tomography. Four sample types were studied in this work: one non-woven sheet without any preservative used for demonstration of the analysis procedure, and three commercially available sheets containing the preservative sandwiched between non-woven and a polyethylene film, for quantitative comparison. The commercially available products are referred to as products A, B and C and actual names are withheld for commercial purposes. The non-woven structure is of interest as it may affect the release rate of the preservative in vapour form, and may also affect the structural integrity of the layered material. Some materials of this type have been known to have the coating delaminate from the non-woven mesh, which can allow direct contact of the active agent with the fruit.

Sample mounting involved a $2.5-\mathrm{mm}$ square placed in a rigid foam fixed on the top of a glass rod. The instrument used in this study is described in more detail in du Plessis et al. (2016a) and was a General Electric Nanotom S, the settings used were $60 \mathrm{kV}$ and $240 \mu \mathrm{A}$. Optimization of scan parameters was performed using the guidelines in du Plessis et al. (2017). Continuous scanning was used with 1600 images recorded in a full rotation of the sample. Acquired X-ray projection images were reconstructed into a 3D data set using system-supplied software. All image analysis was performed in Volume Graphics VGStudioMax 3.0 in this study, but similar procedures as described here can be performed in other software packages.

The first step in the image processing involves de-noising using an adaptive Gauss filter. This is followed by a basic surface determination function, using manual threshold selection such that the material of interest is selected, in addition to noise in the outside of the material. A region of interest (ROI) is selected from the surface, and morphological image operations are applied to first remove internal cavities that might be open to the surface (opening function) and then the closing function is used to remove small noise particles exterior to the material of interest. This new ROI is then used as starting contour for a new advanced surface determination, where local optimization is done for the determination of the surface edge, without human/operator bias. This segmentation is a prerequisite for basic 3D viewing and simple analysis (e.g., volume of fibre material). In order to determine the total material volume including internal pore space of the entire sheet section, a further segmentation was required, involving a sequence of dilation operators followed by erosion operators, effectively determining the edge of the fibrous material but including all internal air space. This was followed by the use of the foam structure analysis module, the wall thickness analysis module as well as the fibre orientation module in VGStudioMax 3.0 using standard settings.

\section{RESULTS AND DISCUSSION}

The basic image segmentation process results in a 3D rendering as shown in Figure 1, for the non-woven material without any additional coating or layers. This material is a polypropylene-based non-woven material used in the production of Sulphur-dioxide $\left(\mathrm{SO}_{2}\right)$ generating sheets. The pads act as a postharvest preservative of fresh produce, by preventing fungal pathogen development, in particular Botrytis cinerea (Mustonen, 1992; Carter et al., 2015). The non-woven functions as a barrier between the fruit and the preservative in accordance to safety regulations. It additionally may prevent or limit $\mathrm{SO}_{2}$ exposure, which may result in phytotoxic effects on the fruit (Crisosto et al., 2002). The fibres are clearly visible and the squares are regions where the fibres have been molten together to keep the mesh together. This basic result can be useful for qualitative inspection purposes as the 3D view can be rotated and 2D virtual cross-sections can be viewed anywhere across the material.

The next analysis step is a fibre orientation analysis, which is shown in Figure 2. The colour-coding shows the orientation vector of each point in space, therefore individual (bent) fibres do not have a single direction value but many directions, as expected for a non- 
woven material. The analysis produces visual information, as well as quantitative values of the mean orientation tensor directions, which can show when more fibres lie in one direction, which could be the case when the production process is not ideal and which will affect the integrity of the material.

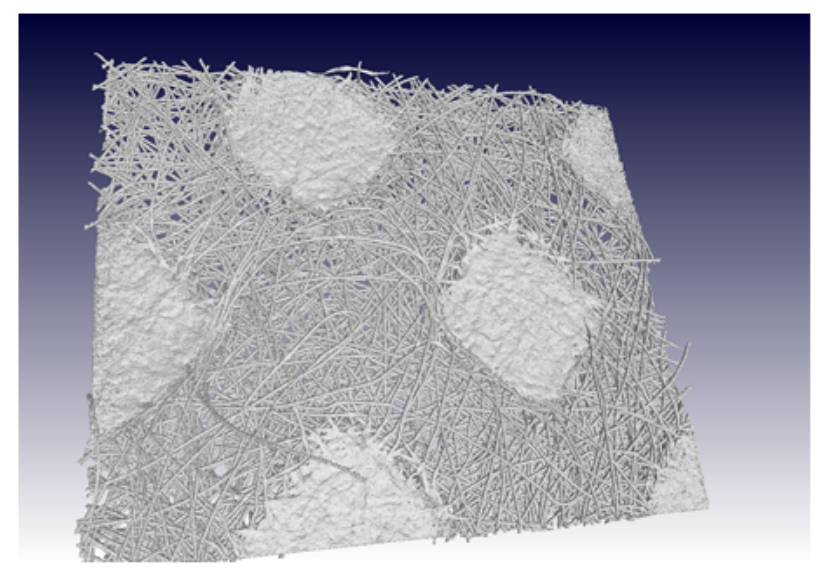

Figure 1. 3D view of a non-woven polymer material, from a high quality microCT scan. The scan resolution is $2 \mu \mathrm{m}$ and the total sample width is $2.5 \mathrm{~mm}$. The squares are typical melted regions holding the non-woven material together.

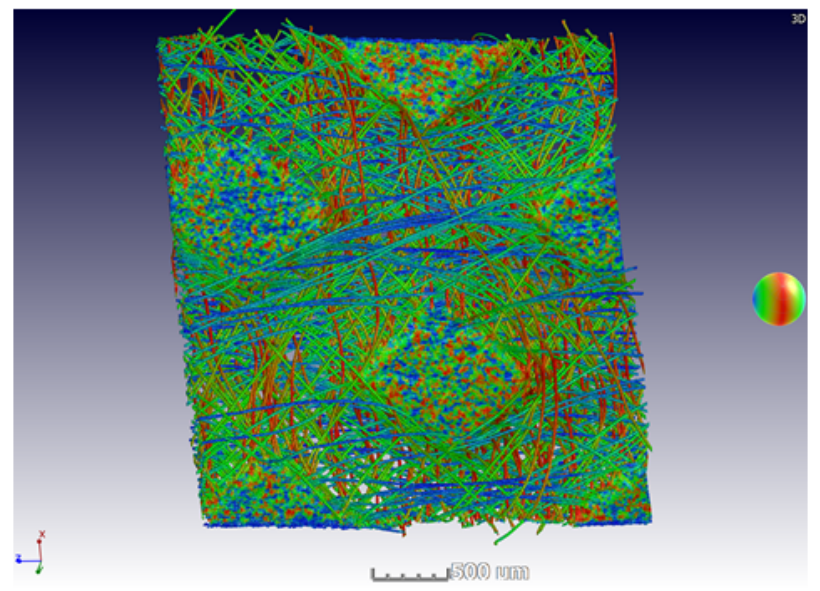

Figure 2. Fibre orientation analysis can be used qualitatively with non-wovens to ensure an even angular distribution. Directionality tensors provide quantitative values, in this case the horizontal and vertical directions have probability tensors of 0.46 and 0.47 respectively indicating an even distribution.

To calculate the pore size distribution, the "foam structure analysis" module of VGStudioMax 3.0 was used. The result in Figure 3 shows a 3D rendering of the pore spaces, each with an individual colour to visually more clearly indicate the pore spaces, while sorting the pore volumes and statistical analysis shows a peak pore diameter at approximately $80 \mu \mathrm{m}$ in this case. This information is valuable in the postharvest industry, because the product efficacy could be closely linked to the amount of gas that is allowed through the material/pores and whether it can efficiently prevent direct contact between the preservative and the fruit, in adherence to safety regulations.

The average fibre thickness can be measured statistically by making use of the "wall thickness analysis" function, as demonstrated in Figure 4. The colour coding shows varying thickness of the material, in this case the fibres are mainly in the region of $16 \mu \mathrm{m}$ in diameter 
while the squares seem to be in the region of 4-6 $\mu \mathrm{m}$. Quantitative analysis results in the form of a histogram is available from this data as shown in Figure 4.

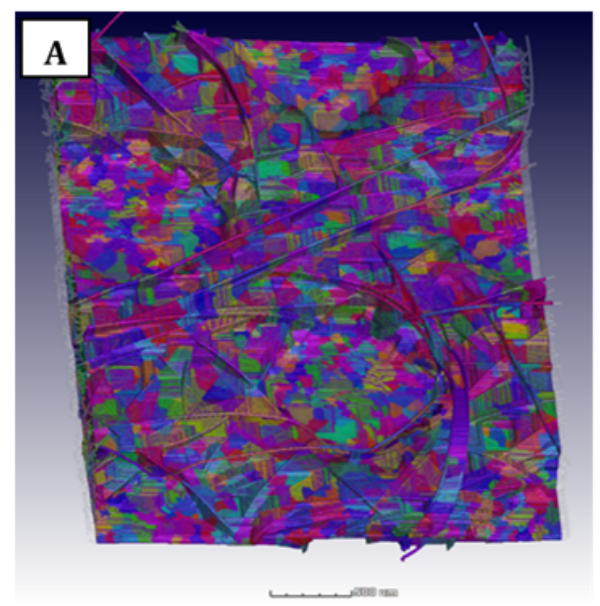

\section{B}

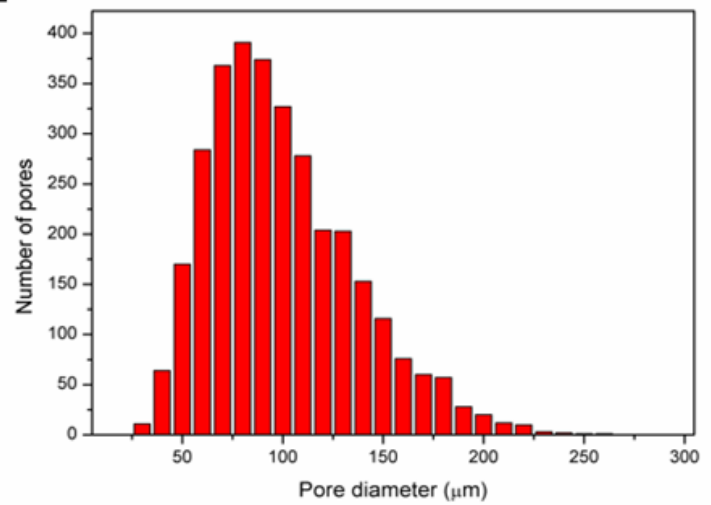

Figure 3. Pore analysis showing (A) 3D image with each individual pore space with a separate colour for qualitative viewing of pore sizes, and (B) statistical pore size distribution histogram.

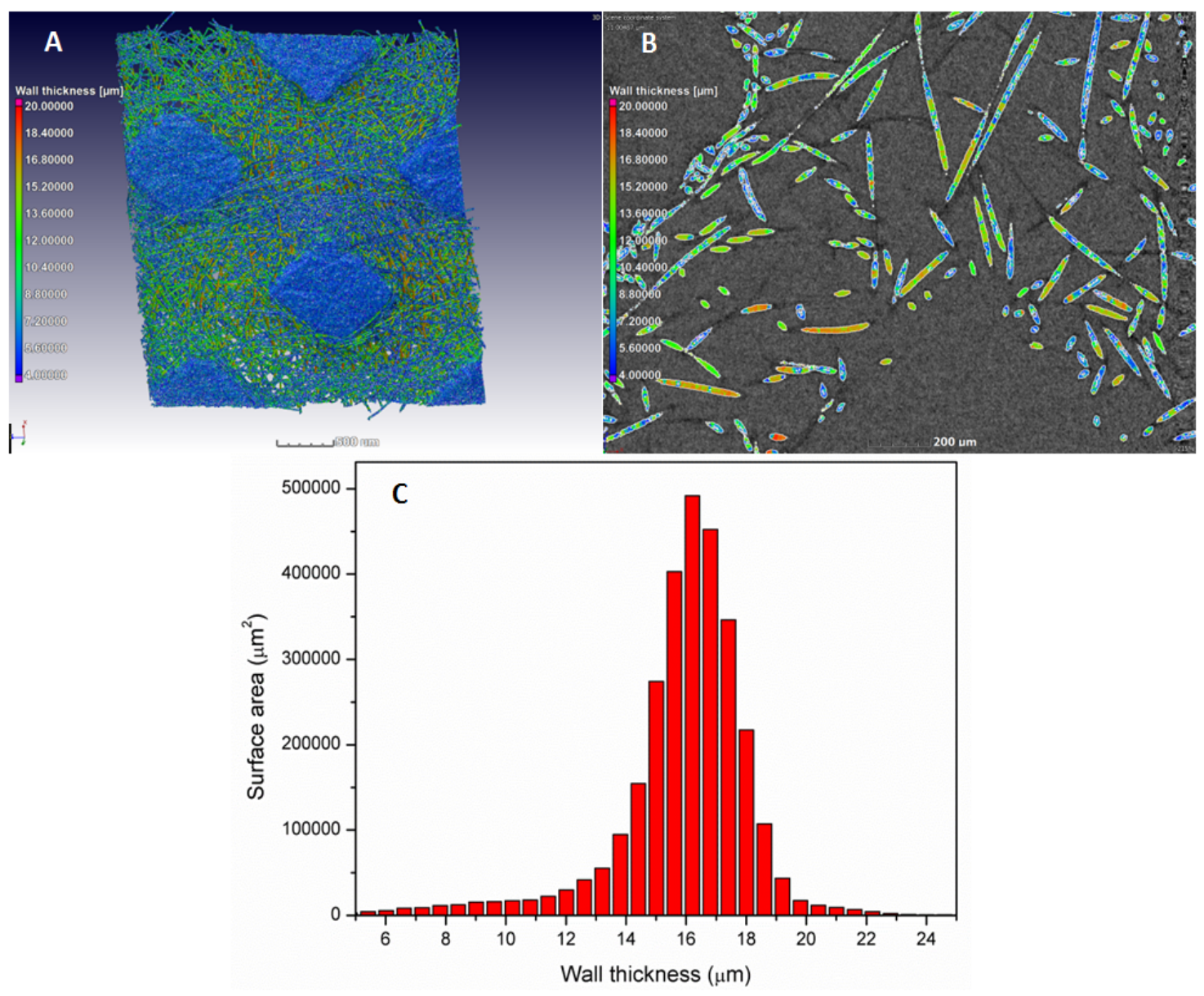

Figure 4. Fibre thickness analysis of non-woven fibres: mean thickness is $16.5 \mu \mathrm{m}$. Shown here are the 3D view (A), a 2D slice view (B) and the wall thickness statistical histogram (C). 
The above method has been used to compare three commercial products - the 3D images of these products are shown in Figure 5 and Table 1 contains the analysis results. The first three samples all have similar values of average pore diameter and total number of pores, while the Product $\mathrm{C}$ sample has significantly more pores and has a smaller average pore size. This indicates a more complex structure, which can negatively affect the release rate of the vapour phase preservative. In all four samples the material volume fraction is between 13 and $20 \%$, but Product $\mathrm{C}$ has thinner and more fibres. A calculation was made whereby the effective number of fibres per volume element can be compared between samples, giving almost identical values for the first three samples but a significantly higher "packing density" value in Product C. This last sample was chosen as a low-quality and cheap product for comparison so differences are to be expected. Specifically, in this case, the thinner fibres require a denser packing to ensure a similar total volume fraction. This may cause differences in the release rate of the preservative and may also affect the structural integrity of the material, especially the adhesion of the coating layer to the non-woven material due to the thinner fibres (a thinner fibre has a smaller cross sectional area of contact with a flat film for adhesion). Additional linear measurements of the molten areas sizes are included, as well as the total thickness of the material in each case, as these could also affect the preservative release rate.

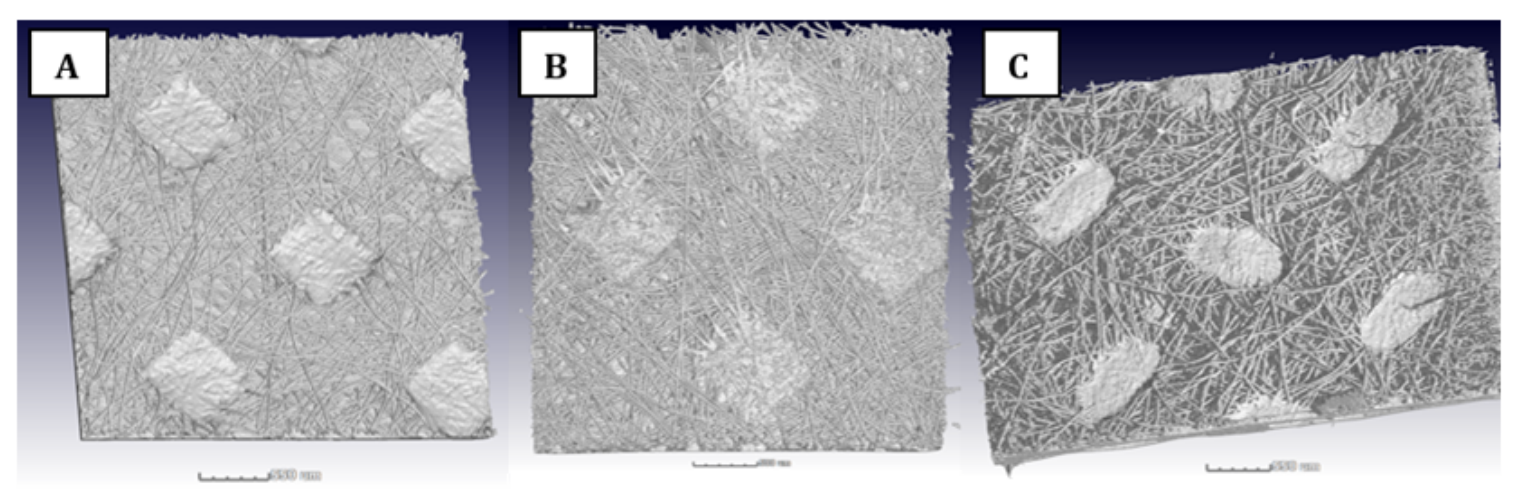

Figure 5. 3D views of different non-woven-containing products $A, B$ and $C$, detailed 3D analysis results shown in Table 1.

Table 1. Comparison between commercial $\mathrm{SO}_{2}$ generating pads and the non-woven materials incorporated into the products.

\begin{tabular}{lcccc}
\hline & Basic non-woven & Product A & Product B & Product C \\
\hline Average pore diameter $(\mu \mathrm{m})$ & 95 & 82 & 85 & 66 \\
Number of pores & 3213 & 3060 & 2683 & 8362 \\
Average fibre material volume fraction $(\%)$ & 13.50 & 19.98 & 16.93 & 14.96 \\
Average fibre thickness $(\mu \mathrm{m})$ & 16.2 & 19.9 & 18.5 & 9.8 \\
Calculated nr of fibres $100 \mu \mathrm{m}^{-3}$ & 6.5 & 6.4 & 6.3 & 19.9 \\
Melt area size $(\mu \mathrm{m})$ & $850 \times 850$ & $600 \times 600$ & $550 \times 550$ & $800 \times 500$ \\
Melt area thickness $(\mu \mathrm{m})$ & 30 & 25 & 50 & 25 \\
Total material thickness $(\mu \mathrm{m})$ & 350 & 200 & 250 & 400 \\
\hline
\end{tabular}

Figure 6 shows two cases where X-ray tomography can assist in identifying problems. The first (Product B) is where the preservative coating (thin layer on top) was applied to the opposite side compared to the molten squares, leaving large pore spaces between the coating and melted squares. These large pore spaces, under changing environmental conditions such as during product transport, can potentially lead to condensation of trapped water vapour and acts to potentially accumulate salt precipitates. The second image (Product C) shows a double-coating where the top coating is not well connected with the 
one below it, leading to easy delamination and exposure of the preservative to the fruit.

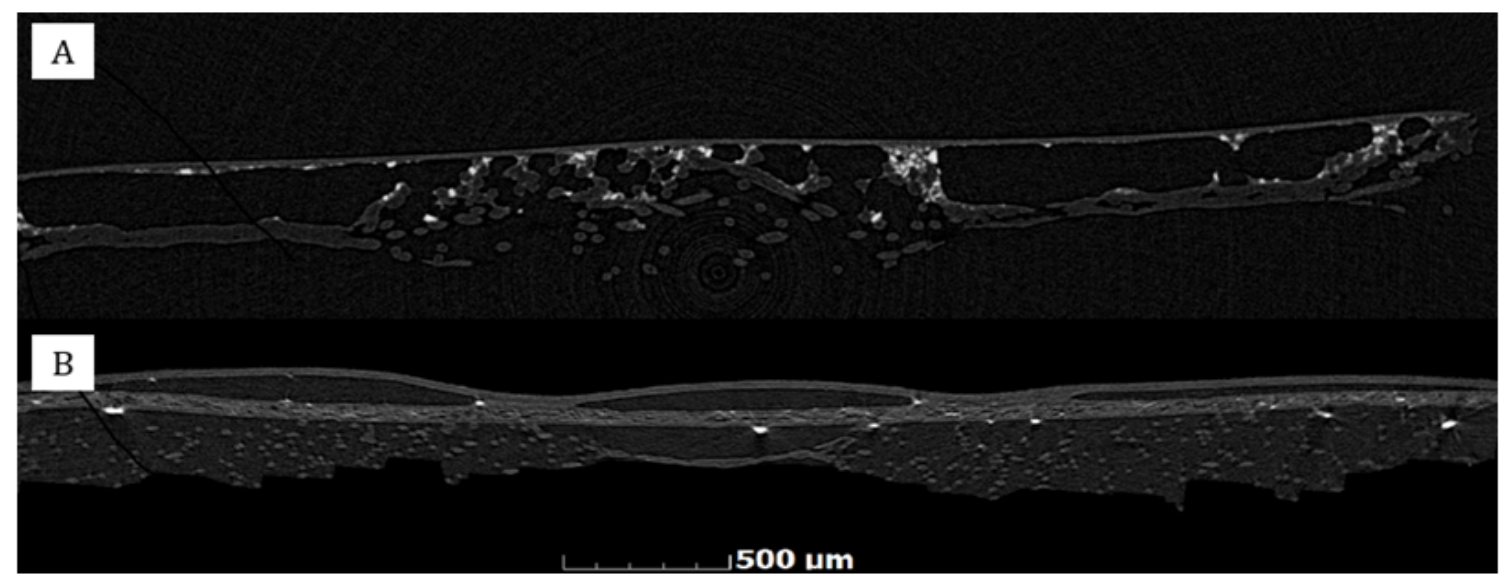

Figure 6. (A) Product B tending to create bubbles and delamination, due to large gaps between melted region (squares) and coating layer (top of this side-view image); (B) Product $\mathrm{C}$ showing delamination of layer and thinner fibres.

\section{CONCLUSIONS}

We have demonstrated the use of X-ray tomography for qualitative and quantitative analysis of $\mathrm{SO}_{2}$ generating pads containing non-woven fibre meshes and used this method to compare different commercially available products. The problem identified in product B can be correlated to the observed crystallization of salts due to the poor resulting permeability and build-up of water vapour, as well as the weaker adhesion of the non-woven with the coating, leading to easier delamination. The delamination observed in the X-ray tomography slice images in product $\mathrm{C}$ has also been observed in practice, as the product is known to delaminate easily and thereby expose the fruit directly to the active agent. In addition, the thinner fibres may lead to poorer permeability relative to the lower packing density of the larger fibres in the other types presented.

The methods used may find application in quality control of these types of materials and in comparison with competitor products. By identifying integral problems with the $\mathrm{SO}_{2}$ generating pads structure on a micron level, proper engineering of the sheet can be ensured to allow for a regulated and controlled release of $\mathrm{SO}_{2}$ during fruit storage. Therefore, a simple method has been developed to provide a fibre packing density value (or number of fibres per unit volume) which correlated well with different manufacturing methods.

\section{Literature cited}

Burheim, O.S., Crymble, G.A., Bock, R., Hussain, N., Pasupathi, S., du Plessis, A., le Roux, S., Seland, F., Su, H., and Pollet, B.G. (2015). Thermal conductivity in the three layered regions of micro porous layer coated porous transport layers for the PEM fuel cell. Int. J. Hydrogen Energy 40 (46), 16775-16785 https://doi.org/10.1016/ j.ijhydene.2015.07.169.

Carter, M.Q., Chapman, M.H., Gabler, F., and Brandl, M.T. (2015). Effect of sulfur dioxide fumigation on survival of foodborne pathogens on table grapes under standard storage temperature. Food Microbiol. 49, 189-196 https://doi.org/10.1016/j.fm.2015.02.002. PubMed

Cnudde, V., and Boone, M.N. (2013). High-resolution X-ray computed tomography in geosciences: a review of the current technology and applications. Earth Sci. Rev. 123, 1-17 https://doi.org/10.1016/j.earscirev.2013. 04.003.

Crisosto, C.H., Palou, L., Garner, D., and Donald, A.A. (2002). Concentration by time product and gas penetration after marine container fumigation of table grapes with reduced doses of sulfur dioxide. Horttechnology 12 (2), 241-245.

du Plessis, A., and Rossouw, P. (2015). Investigation of porosity changes in cast Ti6Al4V rods after hot isostatic pressing. J. Mater. Eng. Perform. 24 (8), 3137-3141 https://doi.org/10.1007/s11665-015-1580-4. 
du Plessis, A., le Roux, S.G., and Guelpa, A. (2016a). The CT scanner facility at Stellenbosch University: an open access X-ray computed tomography laboratory. Nucl. Instrum. Methods Phys. Res. B 384, 42-49 https://doi.org/ 10.1016/j.nimb.2016.08.005.

du Plessis, A., Olawuyi, B.J., Boshoff, W.P., and le Roux, S.G. (2016b). Simple and fast porosity analysis of concrete using X-ray computed tomography. Mater. Struct. 49 (1-2), 553-562 https://doi.org/10.1617/s11527-014-05199.

du Plessis, A., Broeckhoven, C., Guelpa, A., and le Roux, S.G. (2017). Laboratory x-ray micro-computed tomography: a user guideline for biological samples. Gigascience 6 (6), 1-11 https://doi.org/10.1093/ gigascience/gix027. PubMed

Faessel, M., Delisée, C., Bos, F., and Castéra, P. (2005). 3D Modelling of random cellulosic fibrous networks based on X-ray tomography and image analysis. Compos. Sci. Technol. 65 (13), 1931-1940 https://doi.org/10.1016/ j.compscitech.2004.12.038.

Gao, H., Hu, X., Zhang, H., Wang, S., and Liu, L. (2003). Study on sensitivity of table grapes to $\mathrm{SO}_{2}$. Acta Hortic. 628, 541-548 https://doi.org/10.17660/ActaHortic.2003.628.68.

Krause, M., Hausherr, J.M., Burgeth, B., Herrmann, C., and Krenkel, W. (2010). Determination of the fibre orientation in composites using the structure tensor and local X-ray transform. J. Mater. Sci. 45 (4), 888-896 https://doi.org/10.1007/s10853-009-4016-4.

Madra, A., El Hajj, N., and Benzeggagh, M. (2014). X-ray microtomography applications for quantitative and qualitative analysis of porosity in woven glass fiber reinforced thermoplastic. Compos. Sci. Technol. 95, 50-58 https://doi.org/10.1016/j.compscitech.2014.02.009.

Maire, E., and Withers, P.J. (2014). Quantitative X-ray tomography. Int. Mater. Rev. 59 (1), 1-43 https://doi.org/ 10.1179/1743280413Y.0000000023.

Manickam, S.S., and McCutcheon, J.R. (2012). Characterization of polymeric nonwovens using porosimetry, porometry and X-ray computed tomography. J. Membr. Sci. 407-408, 108-115 https://doi.org/10.1016/ j.memsci.2012.03.022.

Mustonen, H.M. (1992). The efficacy of a range of sulfur dioxide generating pads against Botrytis cinerea infection and on out-turn quality of 'Calmeria' table grapes. Aust. J. Exp. Agric. 32 (3), 389-393 https://doi.org/10.1071/ EA9920389.

Ostadi, H., Rama, P., Liu, Y., Chen, R., Zhang, X.X., and Jiang, K. (2010). 3D reconstruction of a gas diffusion layer and a microporous layer. J. Membr. Sci. 351 (1-2), 69-74 https://doi.org/10.1016/j.memsci.2010.01. 031.

Schoeman, L., Williams, P., du Plessis, A., and Manley, M. (2016). X-ray micro-computed tomography ( $\mu \mathrm{CT})$ for non-destructive characterisation of food microstructure. Trends Food Sci. Technol. 47, 10-24 https://doi.org/ 10.1016/j.tifs.2015.10.016.

Soltani, P., Johari, M.S., and Zarrebini, M. (2015). 3D Fiber orientation characterization of nonwoven fabrics using $\mathrm{X}$-ray micro-computed tomography. World Journal of Textile Engineering and Technology 1, 41-47.

Yu, B., Blanc, R., Soutis, C., and Withers, P.J. (2016). Evolution of damage during the fatigue of 3D woven glassfibre reinforced composites subjected to tension-tension loading observed by time-lapse X-ray tomography. Compos., Part A Appl. Sci. Manuf. 82, 279-290 https://doi.org/10.1016/j.compositesa.2015.09.001.

Zhang, H., Wang, S., Xiu, D., Guo, Y., Li, L., Guan, W., Luo, Y., and Kong, Q. (2003). Studies on the relationship of the microstructure of 'Red Globe' grape epidermis, enzyme acitivity and $\mathrm{SO}_{2}$ damage. Acta Hortic. 628, 555-561 https://doi.org/10.17660/ActaHortic.2003.628.70.

Zoffoli, J., Latorre, B.A., and Naranjo, P. (2008). Hairline, a postharvest cracking disorder in table grapes induced by sulphur dioxide. Postharvest Biol. Technol. 47 (1), 90-97 https://doi.org/10.1016/j.postharvbio. 2007.06.013. 